\title{
ABSTRACTS
}

EAR

Effect of Streptomycin on Vestibular Function. J. R. Bignall, London, J. W. Crofton, London, and J. A. B. Thomas, Cardiff. British Medical Journal, I95I, i, 554 .

During the early period of the use of streptomycin in pulmonary tuberculosis, when 2 grams were given daily, disturbances of vestibular function were frequent, but after it had been shown that the daily dose could be halved without reducing the therapeutic effect, the importance of this toxic manifestation diminished, though vestibular dysfunction is still found in about I5 per cent. of patients treated with the usual I gram daily. The authors report their observations in a series of 76 patients with pulmonary tuberculosis receiving streptomycin treatment at the Brompton Hospital, all treated for at least I2 weeks and some for as long as 32 weeks. Tests of vestibular function were carried out on 50 patients. Patients receiving 2 grams of streptomycin a day complained of giddiness almost four times as often as those receiving I gram, and the giddiness was first noticed significantly earlier. Nystagmus and abnormalities in the caloric tests were often associated with a complaint of giddiness. Clinical tests for co-ordination of movement, such as walking along a line with the eyes shut, were useful only when there was gross ataxia. Giddiness and nausea tended to occur in the same patients and about the same time. An attempt was made to prevent vestibular damage by giving antihistamine drugs prophylactically to patients receiving streptomycin. The results suggested that some success was achieved, but the evidence was not conclusive.

\section{R. Scott Stevenson.}

\section{ESOPHAGUS}

Spontaneous Rupture of the Oesophagus. T. A. Grimson, Newcastle-on-Tyne. British Medical Journal, I95I, i, 568.

The author reports a case of spontaneous rupture of the œsophagus in a man aged 66. He was admitted to hospital with a diagnosis of left-sided spontaneous pneumothorax, and had been perfectly well until six hours previously, when, following lunch, he felt sick and vomited. Immediately afterwards he had a severe tearing pain in the left chest and became short of breath ; the pain persisted in spite of half a grain morphine, and the dyspnoa increased. In spite of treatment, penicillin intramuscularly, aspiration of the stomach, and a water-sealed intercostal drain, the patient's condition deteriorated steadily and he died within twelve hours of admission. Post-mortem examination revealed a longitudinal tear $2 \mathrm{~cm}$. in length on the antero-lateral aspect of the osophagus; the mediastinum showed surgical emphysema 


\section{Trachea and Bronchi}

and early mediastinitis ; the œsophagus was normal, except for the longitudinal tear. In almost all recorded cases the patient vomits, usually after a heavy meal, and then suffers a severe tearing pain either over the lower sternum or posteriorly over the lower thoracic and upper lumbar vertebrae. The pain is predominant, and several authors have commented on the lack of relief provided by morphine, as in this case. It is suggested that during the act of vomiting the crico-pharyngeus fails to relax, and there is a rapid rise of the intragastric and intra-œsophageal pressures; when this occurs the osophagus tears at its weakest point, which is at the lower end just above the diaphragm.

R. Scott Stevenson.

\section{TRACHEA AND BRONCHI}

Endobronchial Lipoma: Report of Case. John C. CaRlisle, William V. Leary and John R. McDonald, Rochester, Minn. Proceedings of Staff Meetings of Mayo Clinic, I95I, xxvi, I03.

Endobronchial lipoma is a benign bronchial neoplasm of importance to the clinician chiefly because of two factors: in the first place, although the lesion is benign histologically, it not infrequently causes death owing to associated bronchial obstruction, obstructive pneumonitis and suppurative disease of the lung; secondly, the symptoms and signs of both endobronchial lipoma and bronchogenic carcinoma are in large part secondary to bronchial obstruction. Because of this, not only the clinical picture but also the results of roentgenographic studies of the thorax in cases of endobronchial lipoma may resemble strikingly those of bronchogenic carcinoma. With the advent of bronchoscopy, X-ray surveys of the thorax, and exploratory thoracotomy, benign bronchial neoplasms are no longer rarities, but the authors have found only 9 reports of proved endobronchial lipoma in the literature.

The case report is that of a bus-driver, age 52 , whose chief complaint was that X-rays taken by a mobile unit one month previous to his admission had shown evidence of a lesion in his left lung. On bronchoscopic examination a polypoid tumour covered with mucosa was seen, which obstructed the upper portion of the left upper lobe bronchus. The gross appearance suggested a bronchial adenoma. Biopsy was attempted but was unsatisfactory. The thorax was explored through a left postero-lateral incision, and lobectomy was carried out in the usual manner, the thorax closed with temporary closed drainage and bronchoscopy performed immediately after closure of the skin. The patient had an uneventful convalescence and was discharged with his wound completely healed. Pathological examination showed a soft, yellowgrey tumour, 14 by II mm. in diameter, found in the upper division of the left upper lobe bronchus, almost completely obstructing both the anterior and the apical-posterior divisions of the left upper lobe bronchus. Microscopically the tumour consisted of mature fat cells supported by a delicate fibrous stroma, with scattered bronchial mucous glands in portions of the tumour. It is interesting that simple subcutaneous lipomas constitute about 5 per cent. of all benign tumours of the human body, but endobronchial lipomas are comparatively rare.

R. Scotr Stevenson. 


\section{Abstracts}

\section{MISCELLANEOUS}

Malignancy in Adenomas of the Thyroid. F. H. LAHEY and H. F. HARE, Boston. Journ. Amer. Med. Assoc., r951, cxlv, 689.

It has not been easy to convince many doctors of the danger of malignant change that exists in adenomatous goitre. The figures published in this paper should bring home the realization of this very real danger. The separation of discrete adenomas from multiple ones is of extreme importance. The incidence of proved malignancy in $I, 97 x$ patients with a single nodule was I0.04 per cent. ; in $I, 782$ cases of multiple nodules only 0.62 per cent.; of 440 toxic nodules only 0.68 per cent. were found to be malignant; while the incidence of this change in multiple toxic nodules ( 735 patients) was the lowest of all- 0.54 per cent. These figures prove that the hazard of malignant degeneration in discrete adenomas is not only real but dangerously high. This condition can often be discovered while precancerous and removed with practically no mortality and morbidity. The smaller the adenoma the greater the reason for its removal, as there is less time for the exposure of the host to the danger of malignant change. The younger the person with a discrete adenoma, the less differentiation is there and the higher the incidence of cancer. Therefore, discrete adenomas of any size and in patients of any age, once diagnosed, should be removed.

The authors' preference is towards local excision of the discrete tumour to await the report of the pathologist. Others, however, recommend the complete removal of the lobe. A radical dissection of the neck is carried out when the carcinoma has eroded the capsule and invaded the parenchyma of the thyroid ; also in all cases if they are of Broder's Grade 2 or 3 and have invaded the lymphatics and blood-vessels within the adenoma. The radical dissection includes the complete removal of the affected lobe and isthmus. Postoperative irradiation is used in selected cases.

F. BOYEs KoRKIS. 